\title{
ВПЛИВ ДОБАВКИ ПОЛІПЛАСТ СП-З НА МІЦНІСТЬ ВАЖКОГО БЕТОНУ
}

\section{EFFECT OF POLIPLAST SP-3 ADDITIVE ON THE STRENGTH OF HEAVY CONCRETE}

Олексюк А.С., магістр, Ужегов С.О., к.т.н., Ужегова О.А., к.т.н., доц., Ротко С.В., к.т.н., доц., (Луцький національний технічний університет, м. Луцьк)

Oleksiuk A.S., master, Uzhehov S.O., Ph.D. in Engineering, Uzhehova O.A., Ph.D. in Engineering, Associate Professor, Rotko S.V., Ph.D. in Engineering, Associate Professor, (Lutsk National Technical University, Lutsk)

За допомогою системного аналізу з виконанням математичного моделювання і отриманням рівняння регресї досліджувався вплив на міцність бетону при стиску пластифікатора Поліпласт СП-3, який додавали у кількості 0,5\%, 1,0\% або 1,5\% від витрати цеементу. Разом з тим, досліджувався вплив ше двох факторів: водоцементного співвідномення $i$ температурного режиму твердіння бетону. За рівнянням регресії побудовані поверхні відгуку, які демонструють залежність міџності важкого бетону при стиску від зазначених факторів.

The compressive strength of heavy concrete, as its main mechanical characteristic, is influenced by many factors. It is possible to determine the degree of influence of certain factors using the system analysis with performance of mathematical modeling and getting of the regression equation.

In this article uses the Box-Behnken design, which is often exploited in the study of concrete technology. The purpose of the mathematical method of experiment planning was to determine a mathematical model of this research with a record of the function that will be decisive for the result of the research, based on certain initial conditions. A three-factor experiment was planned, where individual factors did not correlate with each other, and the optimization parameter was the compressive strength of heavy concrete. The effect of Poliplast SP-3 additive, which was added in the amount of $0.5 \%$, $1.0 \%$ or $1.5 \%$ of cement consumption, was experimentally investigated. At the same time, the influence of two more factors was studied: the water-cement ratio $(0.42,0.43$ and 0.44 ) and the temperature of concrete hardening (keeping the experimental samples of concrete in the steaming chamber for 5 hours, keeping other samples within 10 hours, as well as curing of concrete samples under normal conditions without heat treatment).

Based on the experiments, the coefficients of the regression equation were determined statistically. When tested, they showed satisfactory reproducibility of the obtained experimental data - the Cochran's test was $G=0.125$, which is less than the 
tabular value of 0.296. The adequacy of the equation is confirmed by Fisher criterion $F$ $=2.13$, which is less than the tabular $F\left(0.05 ; f_{a d} ; f_{y}\right)=2.23$.

According to the obtained regression equation were modelled the response surfaces, which demonstrate the dependence of the compressive strength of heavy concrete on the content of additive, water-cement ratio, temperature of concrete hardening.

Ключові слова: важкий бетон, міџність, трифакторний експеримент, рівняння регресії, поверхні відгуку.

Key words: heavy concrete, strength, three-factor experiment, regression equation, response surfaces.

На міцність важкого бетону при стиску, як головну його механічну характеристику, впливає багато чинників. Визначити ступінь впливу певних факторів можна за допомогою системного аналізу з виконанням математичного моделювання і отриманням рівняння регресії.

У роботі виконувалось дослідження впливу пластифікатора на міцність бетону методом математичного планування експерименту. Разом 3 кількістю доданого пластифікатора (у \% до маси цементу) варіювалися ще деякі фактори: водоцементне співвідношення та температурний режим твердіння бетону. Таким чином, планувався трифакторний експеримент, де окремі фактори не мали між собою кореляції, а параметром оптимізації була межа міцності бетону при стиску.

Отже, факторами впливу прийнято: $\boldsymbol{X}_{\boldsymbol{I}}$ - вміст пластифікатора у \% до маси цементу; $\boldsymbol{X}_{\mathbf{2}}$ - водоцементне співвідношення, В/Ц; $\boldsymbol{X}_{3}-$ тривалість термообробки у пропарювальній камері.

Для побудови план-матриці експерименту виконано кодування факторів (табл. 1).

Таблиця 1

Умови планування експерименту

\begin{tabular}{|c|c|c|c|c|c|}
\hline \multicolumn{2}{|l|}{ Фактори } & \multirow{2}{*}{\multicolumn{3}{|c|}{$\begin{array}{c}\text { Рівні } \\
\text { варіювання }\end{array}$}} & \multirow{3}{*}{$\begin{array}{c}\text { Інтервал } \\
\text { варіювання }\end{array}$} \\
\hline \multirow[t]{2}{*}{ Натуральний вигляд } & \multirow{2}{*}{$\begin{array}{l}\text { Кодований } \\
\text { вигляд }\end{array}$} & & & & \\
\hline & & -1 & 0 & +1 & \\
\hline Вміст пластифікатора, \% & $x_{1}$ & 0,5 & 1,0 & 1,5 & 0,5 \\
\hline $\begin{array}{l}\text { Водоцементне } \\
\text { співвідношення, В/Ц }\end{array}$ & $x_{2}$ & 0,42 & 0,43 & 0,44 & 0,01 \\
\hline Час пропарювання, годин & $x_{3}$ & 0 & 5 & 10 & 5 \\
\hline
\end{tabular}

Усі фактори мають високий ступінь управління, що дає можливість вибрати заданий рівень варіювання: на основному рівні планування (0), на нижньому рівні $(-1)$ і на верхньому рівні $(+1)$.

Всі параметри дослідних зразків відповідали матриці плану експерименту. У кожній точці плану виготовляли по три зразки, а на основному рівні - шість зразків. 
Для виготовлення бетонної суміші було використано:

цемент М300, виробник - ВАТ Івано-Франківськ-цемент, с. Ямниця;

кварцовий пісок 3 кар'єру с. Носачевичі Рожищенського району Волинської області. Лабораторним шляхом визначені показники: вологість піску 7,15\%; вміст пилуватих і глинистих часток $6,8 \%$; модуль крупності $\mathrm{M}_{\text {кр }}=1,54$. Висновок: пісок дрібний з високим вмістом глини, тому в лабораторії додатково було здійснене відмулювання піску;

щебінь використано з Вирівського щебеневого кар'єру. Щебінь сірий, кубовидний. Просівом крізь сита встановлено: фракція 5-25.

Бетонну суміш складу $1: 1,45: 2,55$ готували у бетонозмішувачі, формування зразків (у вигляді кубів зі стороною 150 мм) з ущільненням суміші здійснювали на вібростолі. Твердіння зразків відбувалося відповідно до матриці плану: одна частина кубів тверділа за нормальних умов - у ванні з гідравлічним замком, іншу частину бетонних кубів поміщали у пропарювальну камеру і витримували там 5 годин, решта кубів залишалася в пропарювальній камері ще на 5 годин. Для пропарювання зразків дотримувались встановленого температурного режиму камери (табл. 2).

Таблиця 2

Температурний режим у пропарювальній камері

\begin{tabular}{|l|c|c|c|c|c|c|c|c|c|c|}
\hline Год. & 1 & 2 & 3 & 4 & 5 & 6 & 7 & 8 & 9 & 10 \\
\hline $\mathrm{t}^{\circ} \mathrm{C}$ & 30 & 39 & 42 & 45 & 53 & 60 & 65 & 70 & 71 & 72 \\
\hline
\end{tabular}

Після пропарювання всі зразки витримували у ванні з гідравлічним замком аж до випробування на стиск. Випробування кубів виконували у віці 28 діб на пресі П-50 (рис.1).
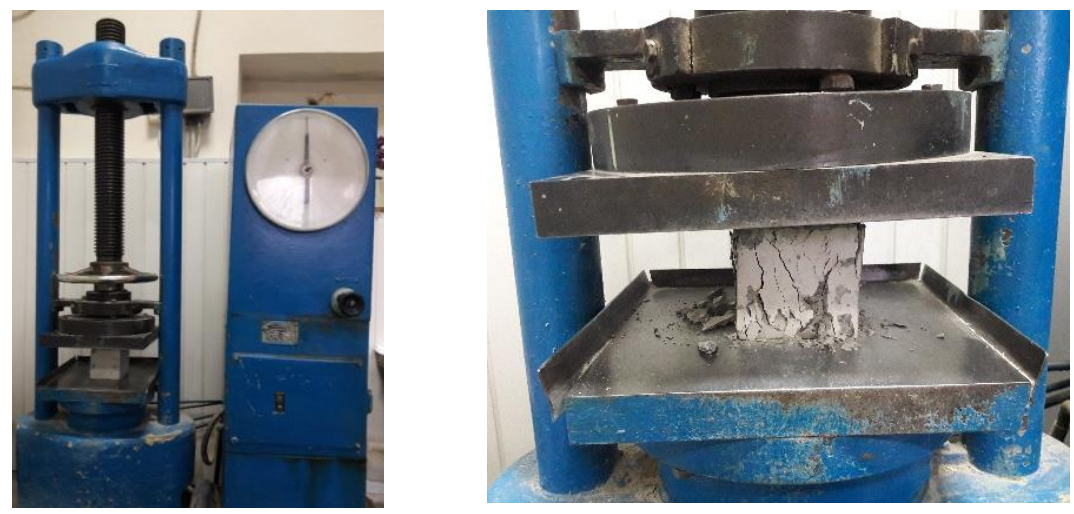

Рис. 1. Випробування зразків на пресі 
При випробуванні зразків для кожного 3 них було встановлене руйнівне зусилля, за яким була визначена міцність на стиск, а також їх середні значення $\bar{y}_{\text {u }}$ (табл. 3).

Таблиця 3

Матриця плану та вихідні експериментальні дані

\begin{tabular}{|c|c|c|c|c|c|c|c|}
\hline \multirow{2}{*}{$\begin{array}{c}\text { Точки } \\
\text { плану }\end{array}$} & \multicolumn{2}{|c|}{ Матриця планування } & \multicolumn{4}{|c|}{ Вихідні параметри, $\boldsymbol{f}_{\boldsymbol{c k}}$, МПа } \\
\cline { 2 - 7 } & $x_{1}$ & $x_{2}$ & $x_{3}$ & $f_{\boldsymbol{c k l}}\left(y_{u l}\right)$ & $\boldsymbol{f}_{\boldsymbol{c k} 2}\left(y_{u 2}\right)$ & $\boldsymbol{f}_{\boldsymbol{c k} 3}\left(y_{u 3}\right)$ & $\boldsymbol{f}_{\boldsymbol{c m}}\left(\bar{y}_{\mathrm{u}}\right)$ \\
\hline 1 & +1 & +1 & 0 & 36.8 & 36.7 & 36.7 & 36.7 \\
\hline 2 & +1 & -1 & 0 & 43.7 & 43.6 & 43.6 & 43.6 \\
\hline 3 & -1 & +1 & 0 & 35.1 & 35.0 & 35.1 & 35.1 \\
\hline 4 & -1 & -1 & 0 & 43.1 & 43.0 & 43.2 & 43.1 \\
\hline 5 & +1 & 0 & +1 & 43.1 & 43.2 & 43.1 & 43.1 \\
\hline 6 & +1 & 0 & -1 & 41.2 & 41.3 & 41.3 & 41.3 \\
\hline 7 & -1 & 0 & +1 & 41.2 & 41.1 & 41.1 & 41.1 \\
\hline 8 & -1 & 0 & -1 & 38.8 & 38.9 & 38.9 & 38.9 \\
\hline 9 & 0 & +1 & +1 & 38.3 & 38.4 & 38.3 & 38.3 \\
\hline 10 & 0 & +1 & -1 & 35.5 & 35.4 & 35.4 & 35.4 \\
\hline 11 & 0 & -1 & +1 & 49.4 & 49.3 & 49.3 & 49.3 \\
\hline 12 & 0 & -1 & -1 & 46.1 & 46.0 & 46.0 & 46.0 \\
\hline 13 & 0 & 0 & 0 & 42.6 & 42.5 & 42.5 & \multirow{2}{*}{} \\
\hline 14 & 0 & 0 & 0 & 42.4 & 42.6 & 42.5 & 42.5 \\
\hline
\end{tabular}

На основі матриці плану Бокса-Бенкена було визначено розрахункові параметри та обчислені коефіцієнти при лінійних членах, квадратичних членах i взаємодіях. Коефіцієнти рівняння регресії визначали за формулами (2.48)...(2.51) посібника [5].

Наступним етапом $\epsilon$ перевірка відтворюваності отриманих дослідних даних. Дисперсію $S_{u}^{2}$ знаходили за формулою:

$$
S_{u}^{2}=\frac{1}{r-1} \sum_{i=1}^{r}\left(y_{u i}-\overline{y_{u}}\right)^{2},
$$

де $\boldsymbol{i}$ - номер повторності; $\boldsymbol{y}_{\boldsymbol{u}}-$ вихідний параметр при $\boldsymbol{i}$-ій повторності.

Дисперсія відтворюваності за [5] становила:

$$
S_{y}^{2}=\frac{1}{N} \sum_{u=1}^{N} S_{u}^{2}=0,16 / 14=0,01143 \mathrm{MПа}^{2} .
$$

Критерій Кохрена за [5]: $G=S_{u, \max }^{2} / \sum_{u=1}^{N} S_{u}^{2}=0,02 / 0,16=0,125$, що $\epsilon$ меншим від табличного значення 0,296, отже, робимо висновок, що процес відтворюваний. 
Табличне значення критерію Стьюдента $t=2,05$ [5, с. 153-154] при рівні значимості $\alpha=0,05(P=5 \%)$ i $f_{y}=N(r-1)=14(3-1)=28$.

Оскільки процес відтворюваний, то можна записати рівняння регресії 3 кодованими факторами:

$$
\begin{aligned}
y & =42.5+0.65 x_{1}-3.65 x_{2}+1.02 x_{3}-1.47 x_{1}{ }^{2}-1.61 x_{2}{ }^{2}+1.34 x_{3}^{2}+ \\
& +0.138 x_{1} x_{2}-0.05 x_{1} x_{3}-0.05 x_{2} x_{3}
\end{aligned}
$$

Адекватність цього рівняння перевіряють за критерієм Фішера $\boldsymbol{F}$. Адекватність буде властива, коли виконуватиметься нерівність:

$$
\boldsymbol{F}=S_{a d}^{2} / S_{y}^{2}<\boldsymbol{F}\left(0,05 ; f_{a d} ; f_{y}\right),
$$

де $\boldsymbol{S}_{\boldsymbol{a d}}^{2}$ - дисперсія адекватності, яку обчислюють за формулою:

$$
S_{a d}^{2}=\frac{1}{n-k-1} \sum_{u=1}^{n}\left(y-\bar{y}_{u}\right)^{2},
$$

тут $\boldsymbol{y}$ - розрахункове значення відгуку в $\boldsymbol{u}$-тому досліді; $\boldsymbol{f}_{\boldsymbol{a d}}$ - число ступенів свободи дисперсії адекватності $\boldsymbol{f}_{\boldsymbol{a d}}=\boldsymbol{n} \boldsymbol{- \boldsymbol { k }}-\boldsymbol{1} ; \boldsymbol{k}$ - число факторів, в даному випадку $\boldsymbol{k}=3 ; \boldsymbol{f}_{\boldsymbol{y}}-$ число ступенів свободи дисперсії відтворюваності $\boldsymbol{f}_{\boldsymbol{y}}=\boldsymbol{n}\left(\boldsymbol{m}_{\boldsymbol{0}}-\boldsymbol{1}\right) ; \boldsymbol{m}_{\boldsymbol{0}}-$ число повторностей, в даному випадку $m_{0}=3$;

Табличне значення критерію Фішера $\boldsymbol{F}$ при числі ступенів свободи дисперсії адекватності $\boldsymbol{f}_{\boldsymbol{a d}}=\boldsymbol{n}-\boldsymbol{k}-\boldsymbol{1}=\mathbf{1 4}-\mathbf{3}-\boldsymbol{1}=\boldsymbol{1 0}$ і при числі ступенів свободи дисперсії відтворюваності $f_{y}=n\left(m_{0}-1\right)=14(3-1)=28$ становить $F\left(0,05 ; f_{a d} ; f_{y}\right)=2,23$.

Для досліду №1 відгук

$$
\begin{aligned}
y^{(1)} & =42.5+0.65 x_{1}-3.65 x_{2}+1.02 x_{3}-1.47 x_{1}^{2}-1.61 x_{2}^{2}+1.34 x_{3}{ }^{2}+ \\
& +0.138 x_{1} x_{2}-0.05 x_{1} x_{3}-0.05 x_{2} x_{3}= \\
= & 42.5+0.65 \times(+1)-3.65 \times(+1)+1.02 \times 0-1.47 \times(+1)^{2}-1.61 \times(+1)^{2}+ \\
& +1.34 \times 0^{2}+0.138 \times(+1) \times(+1)-0.05 \times(+1) \times 0-0.05 \times(+1) \times 0=36.558 .
\end{aligned}
$$

для інших дослідів: $y^{(2)}=43.583 ; y^{(3)}=35.083 ; y^{(4)}=43.441 ; y^{(5)}=43.099 ; y^{(6)}$ $=41.265 ; y^{(7)}=41.359 ; y^{(8)}=39.045 ; y^{(9)}=38.251 ; y^{(10)}=35.511 ; y^{(11)}=49.351$; $y^{(12)}=46.011 ; y^{(13)}=y^{(14)}=42.5$.

Відповідне значення $\left(y-\bar{y}_{u}\right)^{2}$ для першого досліду $(36.558-36.7)^{2}=$ 0,02016; аналогічно для досліду №2 0,00029 ; для досліду №3 0,00029; для досліду №4 0,11628; для досліду №5 0,000001; для досліду №6 0,00122; для досліду №7 0,06708; для досліду №8 0,02103; для досліду №9 $\mathbf{0 , 0 0 2 4 ; ~}$ 
для досліду №10 $\mathbf{0 , 0 1 2 3 2 ; ~ д л я ~ д о с л і д у ~ № 1 1 ~} \mathbf{0 , 0 0 2 6}$; для досліду №12 0,00012; для досліду №13 0,0;для досліду №14 0,0.

Дисперсія адекватності

$s_{a d}^{2}=\frac{1}{n-k-1} \sum_{u=1}^{n}\left(y-\bar{y}_{u}\right)^{2}=\frac{1}{10}(0,02016+0,00029+0,00029+0,11628+$ $0,000001+0,00122+0,06708+0,02103+0,0024+0,01232+0,0026+0,00012)$ $=0,2438 / 10=0,02438$.

$\mathrm{s}_{\mathrm{y}}^{2}=\frac{1}{\mathrm{n}} \sum_{u=1}^{n} s_{u}^{2}=\frac{1}{14} 0,16=0,011428 \mathrm{MПа}^{2}$.

Отже, при дисперсії адекватності $\boldsymbol{s}_{\boldsymbol{a d}}^{2}=\mathbf{0 , 0 2 4 3 8}$; дисперсії відтворюваності $\mathrm{s}_{\mathrm{y}}^{2}=\mathbf{0 , 0 1 1 4 2 8}$ розрахункове значення критерію Фішера становитиме: $\boldsymbol{F}=\frac{\boldsymbol{s}_{a d}^{2}}{\boldsymbol{s}_{y}^{2}}=\frac{\boldsymbol{0 , 0 2 4 3 8}}{\mathbf{0 , 0 1 1 4 2 8}}=2,13$, який менший від табличного значення $\boldsymbol{F}\left(\boldsymbol{0}, 05 ; f_{a d} ; f_{y}\right)=2,23$, отже, робимо висновок, що рівняння регресії адекватне.

За рівнянням регресії побудовані поверхні відгуку (рис. 2, 3, 4).

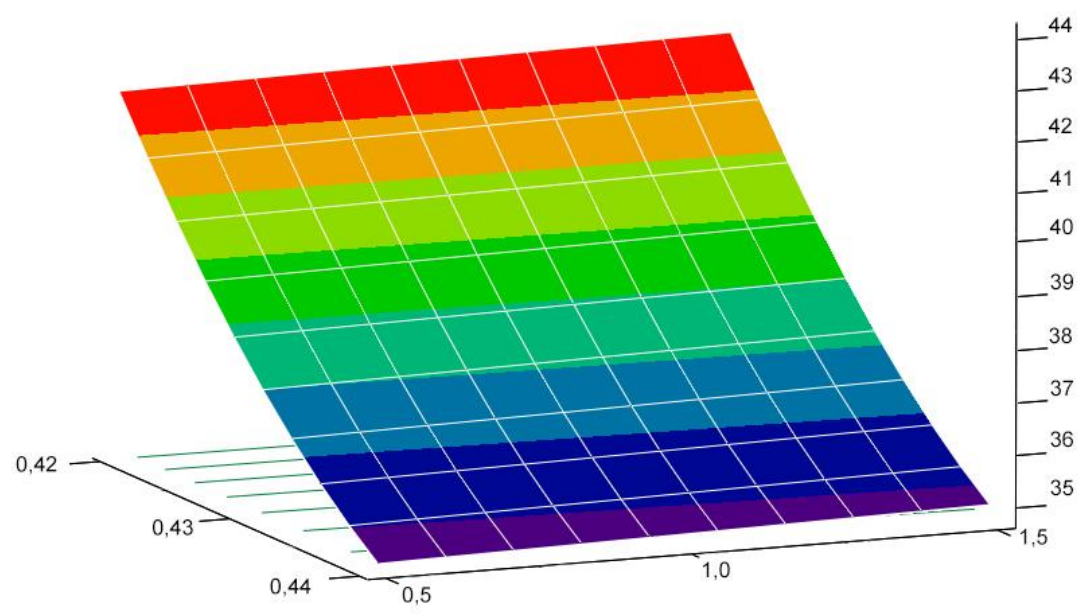

Рис. 2. Залежність міцності бетону при стиску від водоцементного співвідношення та вмісту пластифікатора 


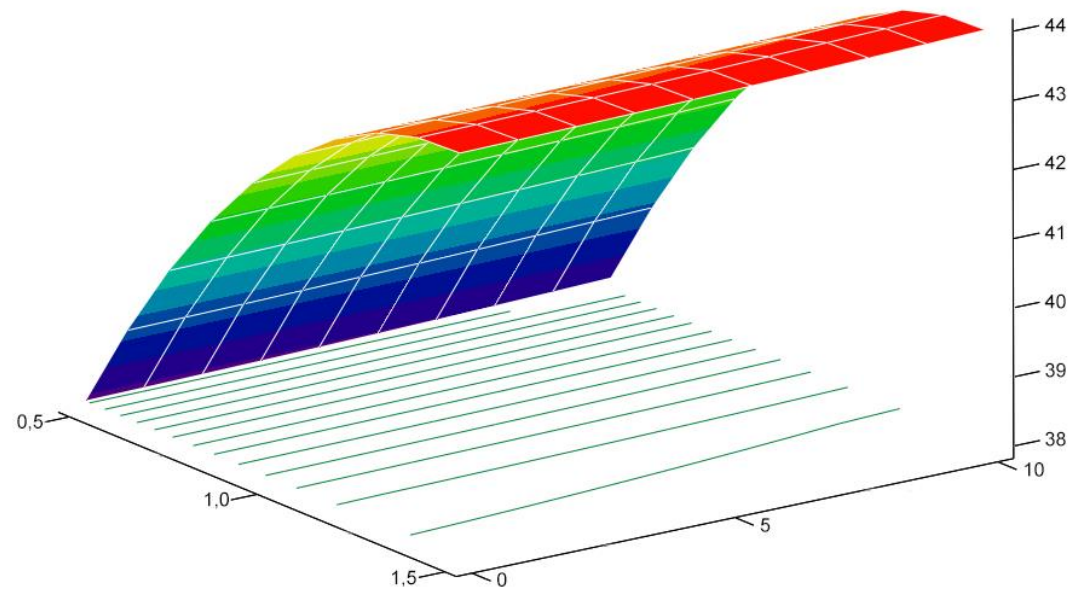

Рис. 3. Залежність міцності бетону при стиску від вмісту пластифікатора і часу пропарювання

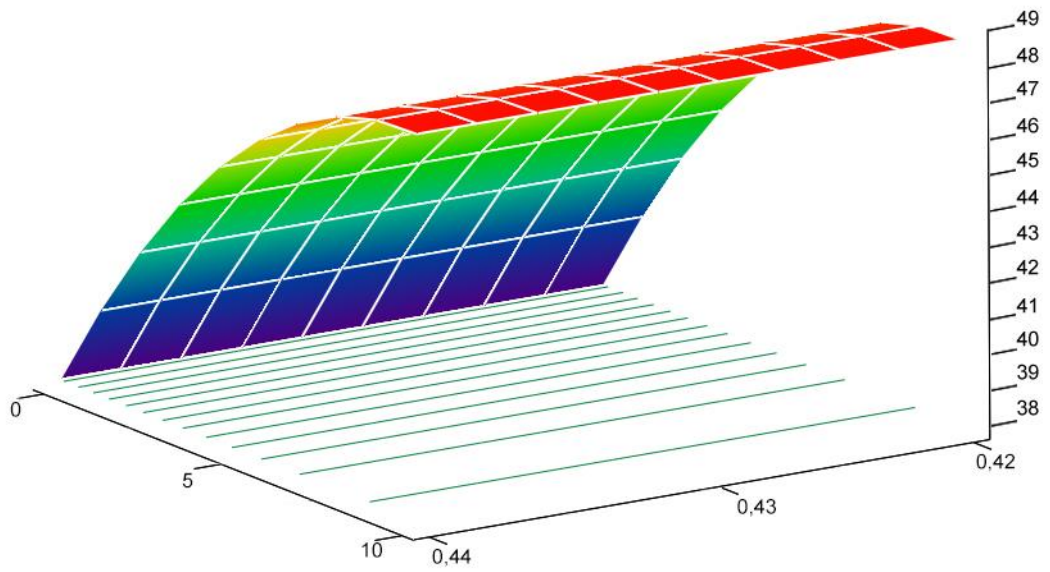

Рис. 4. Залежність міцності бетону при стиску від часу пропарювання та водоцементного співвідношення

Висновки. Дослідження показали, що введення добавки Поліпласт СП-3 до складу суміші в кількості $0,5 \ldots .1,5 \%$ від маси цементу збільшує міцність бетону на 15-24\%. При додаванні Поліпласт СП-3 в кількості 1\%, при $\mathrm{B} / Ц=0,42$ та витримуванні протягом 10 годин у пропарювальній 
камері був отриманий бетон, який показав у віці 28 діб міцність при стиску 49,3 МПа, що більше на 37,7\% у порівнянні з контрольним складом.

\section{References}

1. DSTU B V.2.7-171:2008. Budivelni materialy. Dobavky dlia betoniv i budivelnykh rozchyniv. Zahalni tekhnichni umovy (EN 934-2:2008, NEQ).

2. DSTU B V.2.7-171:2008 (elektronnyi resurs) - http://document.ua/dobavki-dljabetoniv-i-budivelnih-rozchiniv.-zagalni-tehnich-nor17007.html.

3. DSTU B V.2.7-69-98 (HOST 30459-96) Dobavky dlia betoniv. Metody vyznachennia efektyvnosti (elektronnyi resurs) - http://www.stroynote.com. ua/ construction -regulations/document-848.html.

4. DSTU B V.2.7-65-97 Dobavky dlia betoniv i budivelnykh rozchyniv. Klasyfikatsiia (elektronnyi resurs) - http://proxima.com.ua/dbn/articles.php? clause $=413$.

5. Dvorkin L.Y. Rozviazuvannia budivelno-tekhnolohichnykh zadach metodamy matematychnoho planuvannia eksperymentu / L.Y. Dvorkin, O.L. Dvorkin, V.V. Zhytkovskyi: Navch. posibnyk. Rivne: NUVHP, 2011. - 174 s.

\section{Список використаної літератури}

1. ДСТУ Б В.2.7-171:2008. Будівельні матеріали. Добавки для бетонів i будівельних розчинів. Загальні технічні умови (EN 934-2:2008, NEQ).

2. ДСТУ Б В.2.7-171:2008 (електронний ресурс) - http://document.ua/dobavki-dljabetoniv-i-budivelnih-rozchiniv.-zagalni-tehnich-nor17007.html.

3. ДСТУ Б В.2.7-69-98 (ГОСТ 30459-96) Добавки для бетонів. Методи визначення ефективності (електронний ресурc) - http://www.stroynote.com. ua/ construction regulations/document-848.html.

4. ДСТУ Б В.2.7-65-97 Добавки для бетонів і будівельних розчинів. Класифікація (електронний ресурс) - http://proxima.com.ua/dbn/articles.php? clause $=413$.

5. Дворкін Л.Й. Розв'язування будівельно-технологічних задач методами математичного планування експерименту / Л.Й. Дворкін, О.Л. Дворкін, В.В. Житковський: Навч. посібник. Рівне: НУВГП, 2011. - 174 с. 